Revista Brasileira de Farmacognosia Brazilian Journal of Pharmacognosy 22(5): 1092-1103, Sep./Oct. 2012

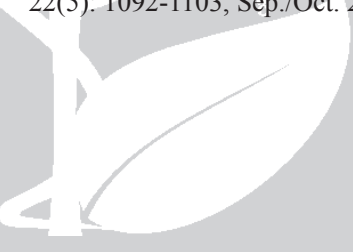

Article

Received 29 Mar 2012

Accepted 3 May 2012

Available online 6 Sep 2012

Keywords:

diabetic neuropathy

hyperalgesia

oryzanol

oxidative stress

ISSN 0102-695X

http://dx.doi.org/10.1590/S0102-

$695 \times 2012005000104$

\section{Protective effect of oryzanol isolated from crude rice bran oil in experimental model of diabetic neuropathy}

\author{
Somsuvra B. Ghatak, Shital S. Panchal
}

Department of Pharmacology, Institute of Pharmacy, Nirma University, India.

\section{Introduction}

Peripheral diabetic neuropathy (DN), the most common and debilitating clinical complication of long-standing diabetes mellitus, affects more than $50-60 \%$ of diabetic patients and is the leading cause of clinically significant morbidities such as pain, decreased motility, foot ulcers, non-traumatic limb amputation and anatomic failure (Sharma et al., 2008; Edwards et al., 2008). Although the pathogenesis is believed to be multifactorial with differing underlying neuroanatomical, neurophysiologic and neurochemical mechanisms (Edwards et al., 2008; Gidal \& Billington, 2006), the duration and severity of hyperglycemia is considered as a universal trigger for the development and progression of DN as well as the other microvascular complications of diabetes such as diabetic nephropathy, neuropathy, and retinopathy (Dobretsov et al., 2007). Several evidences implicate that hyperglycemia triggers various pathogenetic pathways leading to increased glucose flux through the polyol pathway resulting in accumulation of sorbitol and fructose; increased hexosamine pathway flux; excess/inappropriate activation of protein kinase $\mathrm{C}$ (PKC) isoforms thereby initiating a cascade of stress responses; non-enzymatic glycation of proteins yielding "advanced glycation end-products" (AGE) that disrupt neuronal integrity and repair mechanisms and activation of downstream pathways such as mitogen activated protein kinases (MAPK) and poly ADPribose polymerase (PARP) (Sharma et al., 2008; Vincent et al., 2004). Each of these pathways are intertwined and are collectively responsible for causing an imbalance in the mitochondrial redox state of the cell and an increased production as well as decreased scavenging of reactive oxygen species (ROS) resulting in cellular oxidative stress, which if not controlled, leads to a confluence of metabolic and vascular imbalances, including impaired neural function, reduced nerve conduction velocity, loss of neurotrophic support, and apoptosis of neurons and Schwann cells, leading to nerve damage (Kuhad \& Chopra, 2009; Feldman, 2003). Hence, oxidative stress 
may be one of the major pathways involved in the development of DN and an antioxidant can potentially prevent or reverse hyperglycemia-induced nerve dysfunctions. Several antioxidants such as $\alpha$-lipoic acid, taurine, acetyl-L-carnitine, M40403, $\beta$-carotene and tocotrienols have been reported to ameliorate nerve function in experimental $\mathrm{DN}$, thus confirming that attenuating oxidative stress may inhibit the development of the complication (Kuhad \& Chopra, 2009; Sayyed et al., 2006).

Effective disease modifying therapies for DN are currently limited and unsatisfactory on account of their partial effectiveness and associated side effects (Pabreja et al., 2011). In addition, the medical cost associated with diabetes is unsustainable (IDF, 2011). Therefore, renewed interest has been generated in search for more affordable agents from natural origin that retain the therapeutic efficacy and are devoid of side effects.

In the light of this perspective, rice bran oil (RBO) has been the focus of attention because of its balanced fatty acid profile and due to its rich source of bioactive anti-oxidative polyphenols such as, ferulic acid, its esterified derivatives such as OZ, tocopherols, tocotrienols and other associated phenolic compounds (Sugano et al., 1999).

$\mathrm{OZ}$ is a mixture of ferulic acid (4-hydroxy3-methoxycinnamic acid) esters with phytosterols (Lerma-Garcia et al., 2009) and primarily extracted from rice bran. A number of therapeutically useful biological activities have been reported for $\mathrm{OZ}$, such as reduction of cholesterol levels, modulation of the pituitary secretion, inhibition of the gastric acid secretion, antioxidant action and inhibition of the platelet aggregation (Ghatak \& Panchal, 2011). Moreover, OZ has been shown to be very safe with no major side effects being reported in either animal or human studies (Ghatak \& Panchal, 2011).

Furthermore, although previously conducted research has established the hypoglycemic potential of $\mathrm{OZ}$ by virtue of its regulation of adiponectin and insulin secretion and hepatic glucose-regulating enzyme activities (Ohara et al., 2009; Son et al., 2011), the physiological role of $\mathrm{OZ}$ in relation to chronic diabetic complications in experimental animal models is not fully established and requires extensive research. Therefore, the present study was designed to investigate the effect of OZ, a potent free radical scavenger, on nociception and oxidative stress in STZ-induced DN model in rats.

\section{Materials and Methods}

Plant material
Rice bran was procured from Suryodaya Rice Mills, Ahmedabad, Gujarat, India through their milling process.

\section{Extraction of $R B O$}

The extraction of crude RBO from fresh rice bran and its subsequent analysis for the various physicochemical parameters, such as organoleptic characters, specific gravity, viscosity, moisture content, saponification value, unsaponifiable matter, wax content, iodine value, acetyl value, acid value, hydroxyl value, ester value and peroxide value using various standard official methods have been published previously (Ghatak and Panchal, 2010).

\section{Isolation of $\mathrm{OZ}$ from $\mathrm{CRBO}$}

The isolation of $\mathrm{OZ}$ from cRBO using a modified two-step crystallization process previously described by Zullaikah et al. (2009) has been discussed previously (Ghatak \& Panchal, 2012a). The isolated OZ was identified with respect to the standard by melting point determination, thin-layer chromatography (TLC), UV-visible spectrophotometry and high-performance liquid chromatography (HPLC), the results of which have been published recently (Ghatak \& Panchal, 2012b).

\section{Experimental animals}

Adult wistar rats of either sex weighing 250$300 \mathrm{~g}$ were maintained at controlled temperature as well as humidity and fed with standard diet and water provided ad libitium. The experimental protocol was approved by Institutional Animal Ethics Committee (IAEC) of Institute of Pharmacy, Nirma University, as per the guidance of committee for the purpose of Control and Supervision of Experiments on Animals (CPCSEA), Ministry of Social Justice and Empowerment, Government of India.

\section{Dose calculation}

Considering the typical daily dosage of $\mathrm{OZ}$ as $500 \mathrm{mg}$ /day in humans (Drug Information Online, 2012), test doses for rats were selected as 50 and 100 $\mathrm{mg} / \mathrm{kg}$ b.w., $p . o$. based on the dose translation formula on the basis of the body surface area (Reagan-Shaw et al., 2007).

\section{Drugs and reagents}

A pure sample of $\mathrm{OZ}$, as reference standard, was purchased from Tokyo Chemical Industry Co., 
Ltd. Tokyo, Japan. STZ was purchased from Sigma (St. Louis, MO, USA). Glibenclamide was obtained as a gift sample from Torrent Research Centre, Ahmedabad, India. $\mathrm{OZ}$ and glibenclamide were freshly prepared by dissolving in double distilled water after triturating with $4 \%$ Tween 80. A glucose oxidase peroxidase (GODPAP) diagnostic enzyme kit was purchased from Lab Care Diagnostics (India) Pvt. Ltd. All the reagents and chemicals used in the present study were of analytical grade.

\section{Induction and assessment of diabetes}

A single dose of $45 \mathrm{mg} / \mathrm{kg}$ STZ prepared in citrate buffer $(\mathrm{pH} 4.5,0.1 \mathrm{M})$ was injected intravenously to induce diabetes. The age-matched control rats received an equal volume of citrate buffer. Diabetes was confirmed after $48 \mathrm{~h}$ of STZ injection, the blood samples were collected through retro-orbital plexus and plasma glucose levels were estimated by enzymatic glucose oxidase- peroxidase (GOD/POD) diagnostic kit method. The rats having plasma glucose levels $>250$ $\mathrm{mg} / \mathrm{dL}$ (Kuhad et al., 2008) were used for the present study. STZ, a $\beta$-cytotoxin, irreversibly enhances the glycosylation of the pancreatic islet $O$-linked protein in a dose dependent manner and also inhibits the action of $\mathrm{N}$-acetylglucosaminase (O-GlcNAcase) enzyme that removes $O$-linked $N$-acetylglucosamine (O-GlcNAc) from proteins thereby contributing to its diabetogenic toxicity (Konrad et al., 2001). General parameters such as body weight, food and water intake and plasma glucose levels were measured before and at the end of the experiment in order to assess the effect of $\mathrm{OZ}$ on these parameters.

\section{Treatment protocol}

Control and diabetic rats were randomly selected and divided in eight groups of eight animals each. Group 1 animals served as the non-diabetic controls (NC) and received a single vehicle injection of citrate buffer ( $\mathrm{pH} 4.5,0.1 \mathrm{M}$ ) and 4\% Tween 80 . Group 2, 3 and 4 comprised of control treated animals and received OZ $50 \mathrm{mg} / \mathrm{kg}$ (CT-O50), OZ $100 \mathrm{mg} /$ $\mathrm{kg}$ (CT-O100) and standard Glibenclamide $10 \mathrm{mg} /$ $\mathrm{kg}$ (CT-G10) respectively p.o. Group 5 consisted of the diabetic control (DC) and the animals received Tween 80 vehicle p.o. Group 6, 7 and 8 consisted of diabetic animals treated with $\mathrm{OZ}(50 \mathrm{mg} / \mathrm{kg} / \mathrm{day}$, p.o. $)$ (DT-O50), OZ (100 mg/kg/day, p.o.) (DT-O100) and standard Glibenclamide (10 mg/kg/day, p.o.) (DT-G10). All administrations were carried out between 9 am and 11 am daily. Eight weeks following STZ injection, the animals were sacrificed under deep anesthesia, blood was collected from the retro-orbital plexus and plasma was separated. Sciatic nerves were rapidly removed and weighed. A $10 \%(\mathrm{w} / \mathrm{v})$ tissue homogenate was prepared in $0.1 \mathrm{M}$ phosphate buffer ( $\mathrm{pH}$ 7.4). Homogenates were centrifuged at $200 \mathrm{~g}$ for $10 \mathrm{~min}$ at $4{ }^{\circ} \mathrm{C}$ and supernatant was used for the estimation of $\mathrm{Na}^{+}-\mathrm{K}^{+}$ATPase, lipid peroxidation, reduced glutathione, superoxide dismutase catalase and total nitric oxide assay. The samples were stored at $-20{ }^{\circ} \mathrm{C}$ until processed for biochemical estimations.

\section{Behavioral assessment}

\section{Evaluation of nociceptive threshold}

Tail-immersion (hot water) test: tail of rat was immersed in a hot water bath $\left(52.5 \pm 0.5{ }^{\circ} \mathrm{C}\right)$ until tail withdrawal (flicking response) or signs of struggle were observed (cut-off time $12 \mathrm{~s}$ ). Shortening of the tail withdrawal time indicates hyperalgesia and is attributed to central mechanisms (Kannan et al., 1996; Ramabadran et al., 1989).

Tail-immersion (cold water) test: tail of rat was immersed in cold water $\left(10 \pm 0.5{ }^{\circ} \mathrm{C}\right)$ until tail withdrawal (flicking response) or signs of struggle were observed (cut-off time $15 \mathrm{~s}$ ). Shortening of the tail withdrawal time indicates allodynia (Attal et al., 1990).

Hot-plate test: the hyperalgesic response on the hot-plate is considered to result from a combination of central and peripheral mechanisms (Kannan et al., 1996). In this test, animals were individually placed on a hot-plate (Eddy's Hot-Plate) with the temperature adjusted to $55 \pm 1{ }^{\circ} \mathrm{C}$. The latency to the first sign of paw licking or jump response to avoid the heat was taken as an index of the pain threshold; the cut-off time was 10 $\mathrm{s}$ in order to avoid damage to the paw.

\section{Formalin induced flinching}

The rats were briefly allowed to acclimatize in open Plexiglas observation chambers for $30 \mathrm{~min}$ before injecting the nociceptive stimuli. Age-matched control and diabetic animals were gently restrained and injected with $50 \mu \mathrm{L}$ of $0.5 \%$ formalin solution into the dorsal surface of the right hind paw with a 26-gauge needle. Animals were transferred back to the chambers and nociceptive behavior was observed immediately after formalin injection. For data analysis, the behavioral response induced by formalin injection was divided into three phases. Phase 1 was defined as the initial measurement of flinching (1-2 min after formalin injection), the quiescent (Q) phase as the measurements made at 5-6, 10-11 and 15-16 min post formalin injection, and phase 2 as the subsequent periods (20$60 \mathrm{~min}$ ) following formalin injection (Malmberg et al., 
1993). Comparisons of activity during the different phases were made by summing the number of flinches recorded within the time intervals of each phase.

\section{Biochemical assessment}

$\mathrm{Na}^{+}-\mathrm{K}^{+}$ATPase activity was measured in the sciatic nerve tissue homogenate by the method described by Katewa \& Katyare (2003). The malondialdehyde content, a measure of lipid peroxidation, was assayed in the form of thiobarbituric acid-reactive substances by the method of Ohkawa et al. (1979) and expressed as nanomols of malondialdehyde per milligram of protein. Tissue protein estimation was carried out according to the method of Lowry et al. (1951) using bovine serum albumin as the standard. Reduced glutathione (GSH) levels and the activities of various anti-oxidant enzymes like superoxide dismutase (SOD) and catalase (CAT) were assayed in the tissue homogenate as previously established methods (Moron et al., 1979; Misra \& Fridovich, 1972, Aebi, 1983). In vitro quantitative measurement of nitrite level in the sciatic nerve tissue was carried out by the method described by Griess (1879).

\section{Statistical analysis}

All the values were expressed as mean \pm SEM. Statistics was applied using Graph Pad Prism version 5.0 for Windows, Graph Pad software, San Diego, California, USA. One way ANOVA followed by Tukey's multiple comparison test was used to determine the statistical significance between various groups. Differences were considered to be statistically significant when $p<0.05$.

\section{Results}

Effect of OZ on body weight, food and water intake, and blood glucose level in rats

At the end of eight weeks of treatment, STZ produced a significant $(p<0.05)$ decrease in body weight (Figure 1) and a significant $(p<0.05)$ increase in food and water intake (Table 1) in diabetic rats as compared to the control animals. Treatment with OZ (50 and 100 $\mathrm{mg} / \mathrm{kg} /$ day, p.o. $)$ and standard $\mathrm{Gl}(10 \mathrm{mg} / \mathrm{kg} /$ day, p.o. $)$ for eight weeks showed a significant $(p<0.05)$ increase in body weight and a significantly $(p<0.05)$ reduced intake of food and water. Further treatment with $\mathrm{OZ}$ and Gl did not produce any significant changes in body weight, food and water intake in control rats.

STZ treated rat exhibited a significantly $(p<0.05)$ increased serum glucose level as compared to control rats. Chronic treatment with OZ (50 and 100 $\mathrm{mg} / \mathrm{kg} / \mathrm{day}$, p.o.) and standard $\mathrm{Gl}(10 \mathrm{mg} / \mathrm{kg} /$ day, p.o. $)$ in diabetic rats for eight weeks showed a significant $(p<0.05)$ decrease in plasma glucose levels (Figure 2). Treatment with $\mathrm{OZ}(50$ and $100 \mathrm{mg} / \mathrm{kg} /$ day, p.o.) and standard Gl $(10 \mathrm{mg} / \mathrm{kg} / \mathrm{day}$, p.o. $)$ did not produce any significant change in serum glucose level in control rats.

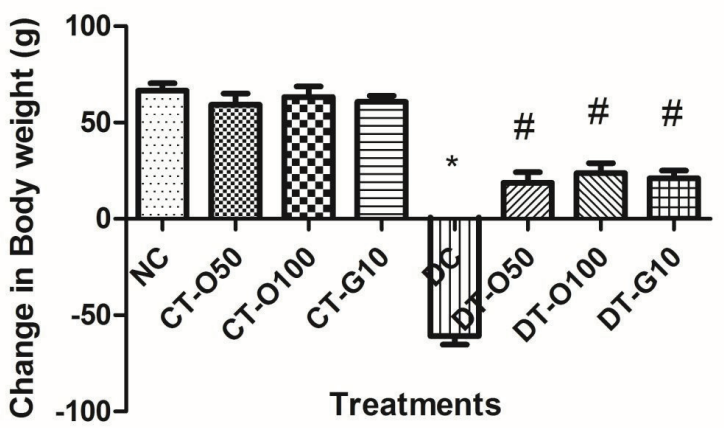

Figure 1. Effect of oryzanol on change in body weight (g) of the rats after eight-week treatment schedule; $n=8$; Values are expressed in mean $\pm \mathrm{SEM}$; NC: Normal control (no treatment); CT-O50: Control treated animals receiving oryzanol $50 \mathrm{mg}$ / $\mathrm{kg}$, orally per day for eight weeks; CT-O100: Control treated animals receiving oryzanol $100 \mathrm{mg} / \mathrm{kg}$, orally per day for eight weeks; CT-G10: Control treated animals receiving standard glibenclamide $10 \mathrm{mg} / \mathrm{kg}$, orally per day for eight weeks; DC: Diabetic control animals induced with a single i.v. injection of streptozotocin, $45 \mathrm{mg} / \mathrm{kg}$ in citrate buffer $(\mathrm{pH} 4.5,0.1 \mathrm{M})$; DT-O50: Diabetic treated animals receiving oryzanol $50 \mathrm{mg} / \mathrm{kg}$, orally per day for eight weeks following STZ injection; DT-O100: Diabetic treated animals receiving oryzanol $100 \mathrm{mg} / \mathrm{kg}$, orally per day for eight weeks following STZ injection; DT-G10: Diabetic treated animals receiving standard glibenclamide $10 \mathrm{mg} / \mathrm{kg}$, orally per day for eight weeks following STZ injection; ${ }^{*} p<0.05$ versus $\mathrm{NC},{ }^{*} p<0.05$ versus DC; Values are obtained by one way ANOVA followed by Tukey's multiple comparison test.

\section{Effect of OZ treatment on nociceptive threshold}

The nociceptive threshold was significantly $(p<0.05)$ lower in diabetic rats compared to the basal values tested in both the tail-immersion (hot and cold water tests) (Figure $3 \mathrm{a}$ and $\mathrm{b}$ ) and hot-plate assays (Figure 3c). Hyperalgesia was manifested in the tailimmersion and hot-plate tests after one and two weeks, respectively. OZ (50 and $100 \mathrm{mg} / \mathrm{kg} /$ day, p.o.) and standard Gl $(10 \mathrm{mg} / \mathrm{kg} /$ day, p.o. $)$ administration to diabetic rats produced a significant $(p<0.05)$ increase in pain threshold as compared to the untreated diabetic rats following eight weeks of treatment. OZ (100 $\mathrm{mg} / \mathrm{kg} / \mathrm{day}$, p.o.) exhibited a higher increase in pain threshold than that of $\mathrm{OZ}(50 \mathrm{mg} / \mathrm{kg} / \mathrm{day}$, p.o. $)$ in both tail-immersion (Figure $3 \mathrm{a}$ and $\mathrm{b}$ ) and hot-plate assays (Figure 3c). 
Table 1. Effect of oryzanol on food $(\mathrm{g})$ and water intake $(\mathrm{ml})$ of the rats after eight-week treatment schedule.

\begin{tabular}{lcc}
\hline \multicolumn{1}{c}{ Groups } & Food Intake $(\mathrm{g})$ & Water Intake $(\mathrm{mL} /$ day $)$ \\
\hline NC & $15.84 \pm 0.2436$ & $24.77 \pm 0.3425$ \\
CT-O50 & $13.54 \pm 0.3027$ & $22.32 \pm 0.3620$ \\
CT-O100 & $11.52 \pm 0.3884$ & $19.88 \pm 0.3879$ \\
CTG-10 & $12.18 \pm 0.3259$ & $20.96 \pm 0.2879$ \\
DC & $26.76 \pm 2.584^{*}$ & $73.28 \pm 8.462^{*}$ \\
DT-O50 & $22.22 \pm 1.533$ & $52.57 \pm 4.832^{\#}$ \\
DT-O100 & $19.57 \pm 1.400^{\#}$ & $48.38 \pm 4.699^{\#}$ \\
DTG-10 & $20.52 \pm 1.523^{\#}$ & $49.92 \pm 4.759^{\#}$
\end{tabular}

$\mathrm{n}=8$; Values are expressed in mean \pm SEM; NC: Normal control (no treatment); CT-O50: Control treated animals receiving oryzanol 50 $\mathrm{mg} / \mathrm{kg}$, orally per day for eight weeks; CT-O100: Control treated animals receiving oryzanol $100 \mathrm{mg} / \mathrm{kg}$, orally per day for eight weeks; CT-G10: Control treated animals receiving standard glibenclamide 10 $\mathrm{mg} / \mathrm{kg}$, orally per day for eight weeks; DC: Diabetic control animals induced with a single i.v. injection of streptozotocin, $45 \mathrm{mg} / \mathrm{kg}$ in citrate buffer ( $\mathrm{pH} 4.5,0.1 \mathrm{M})$; DT-O50: Diabetic treated animals receiving oryzanol $50 \mathrm{mg} / \mathrm{kg}$, orally per day for eight weeks following STZ injection; DT-O100: Diabetic treated animals receiving oryzanol $100 \mathrm{mg} / \mathrm{kg}$, orally per day for eight weeks following STZ injection; DT-G10: Diabetic treated animals receiving standard glibenclamide $10 \mathrm{mg} / \mathrm{kg}$, orally per day for eight weeks following STZ injection; ${ }^{*} p<0.05$ versus $\mathrm{NC},{ }^{*} p<0.05$ versus DC; Values are obtained by one way ANOVA followed by Tukey's multiple comparison test.

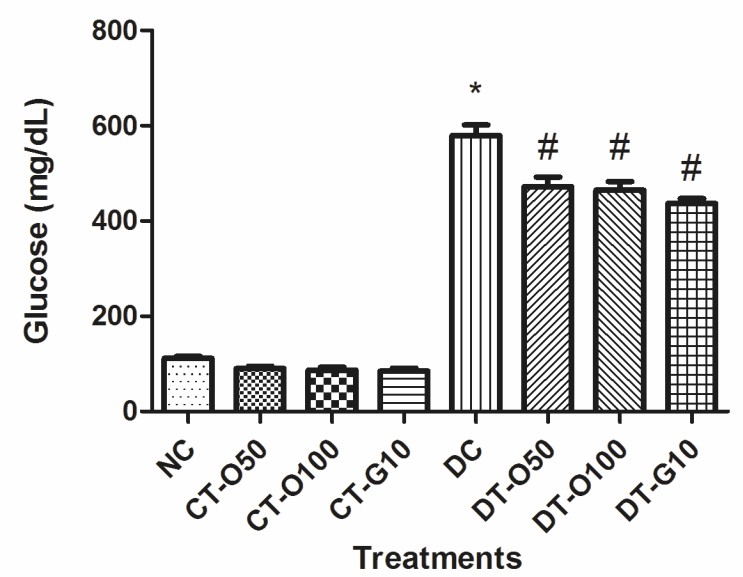

Figure 2. Effect of oryzanol on serum glucose level (mg/ $\mathrm{dL}$ ) of the rats after eight-week treatment schedule; $n=8$; Values are expressed in mean \pm SEM; NC: Normal control (no treatment); CT-O50: Control treated animals receiving oryzanol $50 \mathrm{mg} / \mathrm{kg}$, orally per day for eight weeks; CT-O100: Control treated animals receiving oryzanol $100 \mathrm{mg} / \mathrm{kg}$, orally per day for eight weeks; CT-G10: Control treated animals receiving standard glibenclamide $10 \mathrm{mg} / \mathrm{kg}$, orally per day for eight weeks; DC: Diabetic control animals induced with a single i.v. injection of streptozotocin, $45 \mathrm{mg} / \mathrm{kg}$ in citrate buffer ( $\mathrm{pH} 4.5,0.1 \mathrm{M})$; DT-O50: Diabetic treated animals receiving oryzanol $50 \mathrm{mg} / \mathrm{kg}$, orally per day for eight weeks following STZ injection; DT-O100: Diabetic treated animals receiving oryzanol $100 \mathrm{mg} / \mathrm{kg}$, orally per day for eight weeks following STZ injection; DT-G10: Diabetic treated animals receiving standard glibenclamide $10 \mathrm{mg} / \mathrm{kg}$, orally per day for eight weeks following STZ injection; ${ }^{*} p<0.05$ versus NC, ${ }^{*} p<0.05$ versus DC; Values are obtained by one way ANOVA followed by Tukey's multiple comparison test.
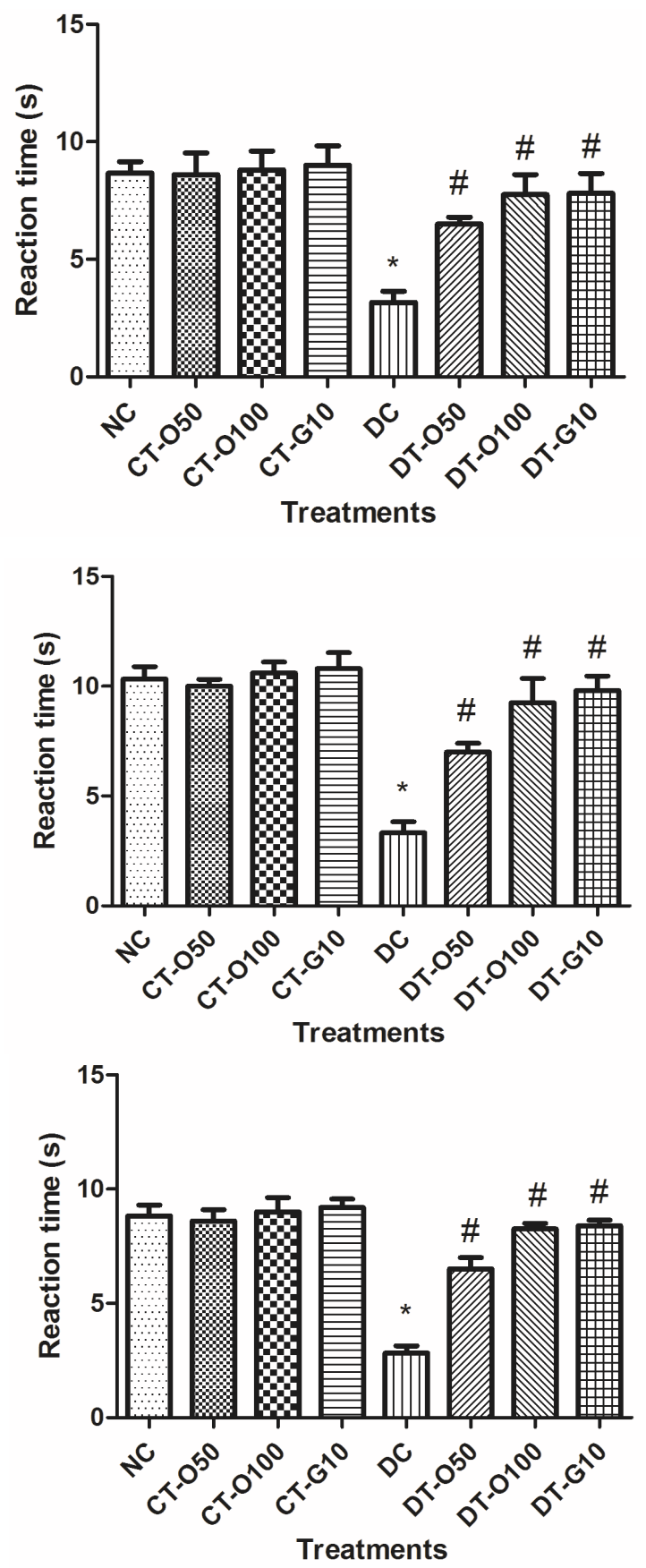

Figure 3. Effect of chronic treatment of oryzanol on pain threshold in rats subjected to (a) warm water tail immersion test (b) cold water tail immersion test (c) hot plate test; $n=8$; Values are expressed in mean \pm SEM; NC: Normal control (no treatment); CT-O50: Control treated animals receiving oryzanol $50 \mathrm{mg} / \mathrm{kg}$, orally per day for eight weeks; CT-O100: 
Control treated animals receiving oryzanol $100 \mathrm{mg} / \mathrm{kg}$, orally per day for eight weeks; CT-G10: Control treated animals receiving standard glibenclamide $10 \mathrm{mg} / \mathrm{kg}$, orally per day for eight weeks; DC: Diabetic control animals induced with a single $i . v$. injection of streptozotocin, $45 \mathrm{mg} / \mathrm{kg}$ in citrate buffer $(\mathrm{pH} 4.5,0.1 \mathrm{M})$; DT-O50: Diabetic treated animals receiving oryzanol $50 \mathrm{mg} / \mathrm{kg}$, orally per day for eight weeks following STZ injection; DT-O100: Diabetic treated animals receiving oryzanol $100 \mathrm{mg} / \mathrm{kg}$, orally per day for eight weeks following STZ injection; DT-G10: Diabetic treated animals receiving standard glibenclamide $10 \mathrm{mg} / \mathrm{kg}$, orally per day for eight weeks following STZ injection; ${ }^{*} p<0.05$ versus $\mathrm{NC}$, ${ }^{\#} p<0.05$ versus DC; Values are obtained by one way ANOVA followed by Tukey's multiple comparison test.

\section{Effect of OZ treatment on formalin-induced flinching}

All the rats subcutaneously challenged with $0.5 \%$ formalin into hind paw produced characteristic biphasic incidence of flinching with an early phase 1 and a late phase 2 separated by a quiescent period (phase Q). Diabetic rats exposed to $0.5 \%$ formalin exhibited a significantly $(p<0.05)$ increased frequency of flinching during both $Q$ phase and phase 2 as compared to the untreated controls. Following injection of $0.5 \%$ formalin, $\mathrm{OZ} \mathrm{(50} \mathrm{and} 100 \mathrm{mg} / \mathrm{kg} / \mathrm{day}$, p.o.) and standard Gl (10 mg/kg/day, p.o.) significantly $(\mathrm{p}<0.05)$ reduced the flinching in diabetic rats during both phase $\mathrm{Q}$ and phase 2 but not in phase 1 (Figure $4 \mathrm{a}$ and $\mathrm{b}$ ). The values, however, were not significantly different from normal or treated controls.

\section{Effect of OZ treatment $\mathrm{Na}^{+}-\mathrm{K}^{+}$ATPase activity from sciatic nerve}

Sciatic nerve $\mathrm{Na}^{+}-\mathrm{K}^{+}$ATPase activity was significantly $(p<0.05)$ reduced in diabetic rats as compared to the normal control (Figure 5). This was significantly $(p<0.05)$ corrected by OZ $(100 \mathrm{mg} / \mathrm{kg} /$ day, p.o.) and standard Gl (10 mg/kg/day, p.o.) treatment after eight weeks.

\section{Effect of $O Z$ on diabetes-induced changes in lipid peroxidation}

Thiobarbituric acid-reactive substance levels were increased significantly $(p<0.05)$ in the sciatic nerves of diabetic rats as compared to the normal control group (Figure 6). Chronic treatment with OZ (50 and $100 \mathrm{mg} / \mathrm{kg} /$ day, p.o. $)$ produced a significant $(p<0.05)$ and dose dependent reduction in thiobarbituric acidreactive substance levels in STZ-treated rats, which was more effective than that exhibited by standard Gl $(10 \mathrm{mg} / \mathrm{kg} / \mathrm{day}$, p.o.).

\section{Formalin induced flinches (Ph-Q)}

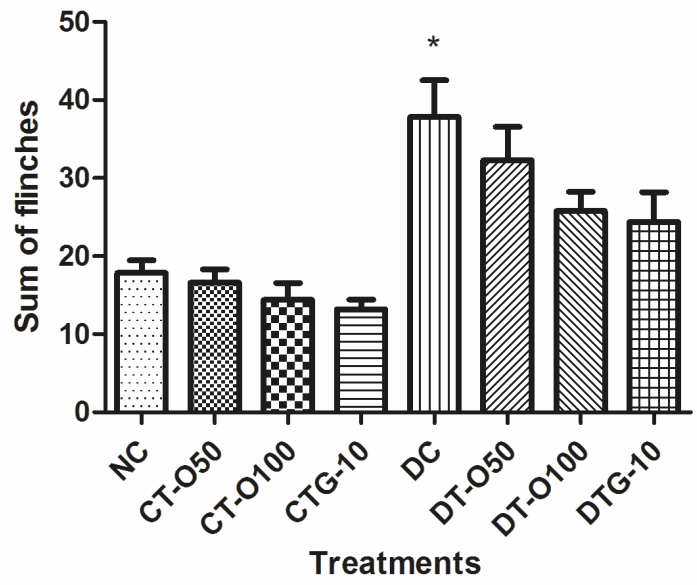

Formalin induced flinches (Ph-2)

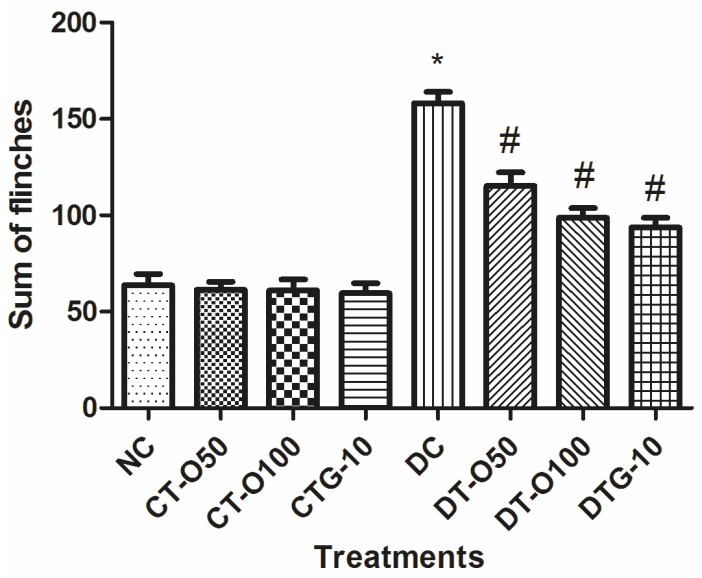

Figure 4. Effect of chronic treatment of oryzanol on paw flinching in rats during (a) phase Q of the $0.5 \%$ formalin test. (b) phase 2 of the $0.5 \%$ formalin test; $n=8$; Values are expressed in mean \pm SEM; NC: Normal control (no treatment); CT-O50: Control treated animals receiving oryzanol $50 \mathrm{mg} / \mathrm{kg}$, orally per day for eight weeks; CT-O100: Control treated animals receiving oryzanol $100 \mathrm{mg} / \mathrm{kg}$, orally per day for eight weeks; CT-G10: Control treated animals receiving standard glibenclamide $10 \mathrm{mg} /$ $\mathrm{kg}$, orally per day for eight weeks; DC: Diabetic control animals induced with a single $i . v$. injection of streptozotocin, $45 \mathrm{mg} /$ $\mathrm{kg}$ in citrate buffer $(\mathrm{pH} 4.5,0.1 \mathrm{M}$ ); DT-O50: Diabetic treated animals receiving oryzanol $50 \mathrm{mg} / \mathrm{kg}$, orally per day for eight weeks following STZ injection; DT-O100: Diabetic treated animals receiving oryzanol $100 \mathrm{mg} / \mathrm{kg}$, orally per day for eight weeks following STZ injection; DT-G10: Diabetic treated animals receiving standard glibenclamide $10 \mathrm{mg} / \mathrm{kg}$, orally per day for eight weeks following STZ injection; ${ }^{*} p<0.05$ versus $\mathrm{NC},{ }^{*} p<0.05$ versus DC; Values are obtained by one way ANOVA followed by Tukey's multiple comparison test. 


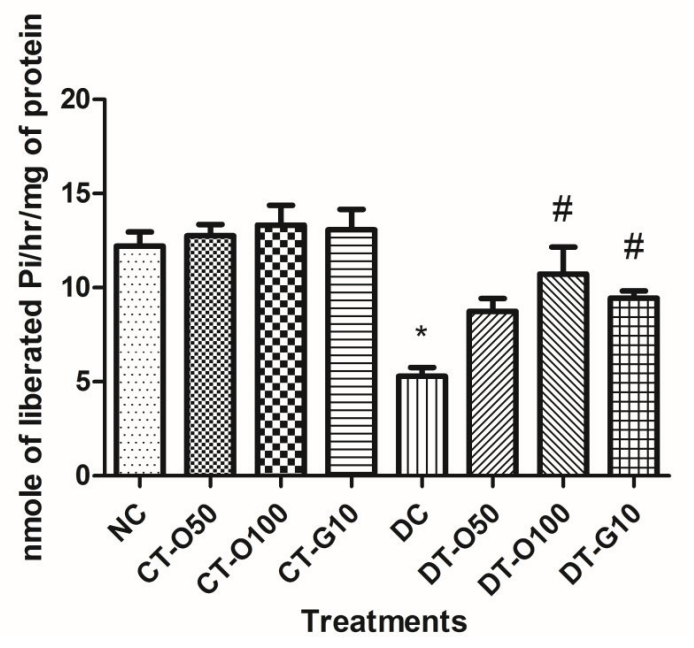

Figure 5. Effect of chronic treatment of oryzanol on sciatic nerve $\mathrm{Na}^{+}-\mathrm{K}^{+}$ATPase activities in rats; $\mathrm{n}=8$; Values are expressed in mean $\pm \mathrm{SEM}$; NC: Normal control (no treatment); CT-O50: Control treated animals receiving oryzanol $50 \mathrm{mg}$ / $\mathrm{kg}$, orally per day for eight weeks; CT-O100: Control treated animals receiving oryzanol $100 \mathrm{mg} / \mathrm{kg}$, orally per day for eight weeks; CT-G10: Control treated animals receiving standard glibenclamide $10 \mathrm{mg} / \mathrm{kg}$, orally per day for eight weeks; DC: Diabetic control animals induced with a single i.v. injection of streptozotocin, $45 \mathrm{mg} / \mathrm{kg}$ in citrate buffer $(\mathrm{pH} 4.5,0.1 \mathrm{M})$; DT-O50: Diabetic treated animals receiving oryzanol $50 \mathrm{mg}$ / $\mathrm{kg}$, orally per day for eight weeks following STZ injection; DTO100: Diabetic treated animals receiving oryzanol $100 \mathrm{mg} / \mathrm{kg}$, orally per day for eight weeks following STZ injection; DT-G10: Diabetic treated animals receiving standard glibenclamide 10 $\mathrm{mg} / \mathrm{kg}$, orally per day for eight weeks following STZ injection; ${ }^{*} p<0.05$ versus $\mathrm{NC},{ }^{*} p<0.05$ versus DC; Values are obtained by one way ANOVA followed by Tukey's multiple comparison test.

\section{Effect of $\mathrm{OZ}$ on diabetes-induced changes in the antioxidant profile}

In the eighth week, the GSH contents and the enzyme activity of superoxide dismutase significantly $(p<0.05)$ decreased in the sciatic nerves of diabetic rats as compared to the normal control group (Figure $7 \mathrm{a}$ and $\mathrm{b}$ ). Although a marked reduction in the levels of catalase was evident in the sciatic nerves of diabetic rats, the difference was not statistically significant when compared to the normal control animals (Figure 7c). The reduction in the levels of GSH was significantly $(p<0.05)$ improved by treatment with OZ $(100 \mathrm{mg} / \mathrm{kg} /$ day, p.o. $)$ and standard $\mathrm{Gl}$ $(10 \mathrm{mg} / \mathrm{kg} / \mathrm{day}$, p.o.) in the sciatic nerves of STZ-treated rats. However, no significant increase in the levels of superoxide dismutase and catalase was observed in treated vs diabetic rats upon administration of OZ (50 and $100 \mathrm{mg} /$ $\mathrm{kg} /$ day, p.o.) and standard Gl (10 mg/kg/day, p.o.) during the eight-week treatment period.

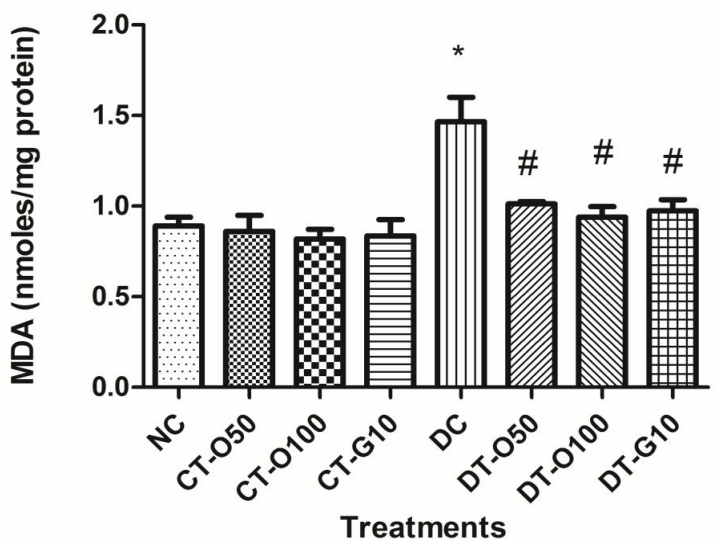

Figure 6. Effect of chronic treatment of oryzanol on lipid peroxidation in sciatic nerve of rats; $n=8$; Values are expressed in mean $\pm \mathrm{SEM}$; NC: Normal control (no treatment); CT-O50: Control treated animals receiving oryzanol $50 \mathrm{mg} /$ $\mathrm{kg}$, orally per day for eight weeks; CT-O100: Control treated animals receiving oryzanol $100 \mathrm{mg} / \mathrm{kg}$, orally per day for eight weeks; CT-G10: Control treated animals receiving standard glibenclamide $10 \mathrm{mg} / \mathrm{kg}$, orally per day for eight weeks; DC: Diabetic control animals induced with a single i.v. injection of streptozotocin, $45 \mathrm{mg} / \mathrm{kg}$ in citrate buffer ( $\mathrm{pH} 4.5,0.1 \mathrm{M})$; DT-O50: Diabetic treated animals receiving oryzanol $50 \mathrm{mg} / \mathrm{kg}$, orally per day for eight weeks following STZ injection; DT-O100: Diabetic treated animals receiving oryzanol $100 \mathrm{mg} / \mathrm{kg}$, orally per day for eight weeks following STZ injection; DT-G10: Diabetic treated animals receiving standard glibenclamide $10 \mathrm{mg} / \mathrm{kg}$, orally per day for eight weeks following STZ injection; ${ }^{*} p<0.05$ versus $\mathrm{NC},{ }^{*} p<0.05$ versus DC; Values are obtained by one way ANOVA followed by Tukey's multiple comparison test.

\section{Effect of $\mathrm{OZ}$ on diabetes-induced nitrosative stress}

Tissue nitrite levels were significantly $(p<0.05)$ elevated in the diabetic rats (Figure 8). OZ (100 mg/ $\mathrm{kg} /$ day, p.o.) and standard Gl (10 mg/kg/day, p.o.) treatment significantly $(p<0.05)$ inhibited this increase in nitrite levels.

\section{Discussion}

In the current study, STZ induced rats exhibited a significantly higher blood glucose level, increased food and water intake and a significantly decreased body weight, lower nociceptive threshold and a reduced grip strength as compared to non-diabetic animals thereby confirming allodynia, thermal hyperalgesia and muscle weakness in diabetic animals. Similar models of thermal hyperalgesia and formalin-induced flinching have been previously reported in STZ-induced animals (Calcutt et al., 1996; Kuhad \& Chopra, 2008; Tembhurne \& Sakarkar, 2010). In the current study, OZ treatment restored body weight, 
blood glucose, food and water intake along with pain threshold, pain perception and neuromuscular strength in diabetic rats.

Large proportions of diabetic patients are characterized by an altered perception threshold coupled with an increased sensitivity to noxious and non-noxious stimuli. The tail-flick test depicts the activity of simple spinal reflex arc by assessing a delay in withdrawing the tail from noxious stimuli (Calcutt, 2001; Ilnytska et al., 2006). Hyperalgesia or the paw withdrawal latencies to noxious thermal stimuli, on the other hand, denotes supraspinal sensory processing (Calcutt, 2001; Obrosova et al., 2005). In the current study, marked thermal hyperalgesia observed in diabetic animals was reversed by treatment with OZ.
In the formalin test, phase 1 responses are indicative of acute noxious stimulation, whereas phase 2 responses are ascribed to the combinatorial effect of the inflammation in the peripheral tissue and functional alterations in the dorsal horn of the spinal cord (Calcutt et al., 1994; Kidd \& Urban, 2001). In the present study, the marked effects of OZ treatment on flinching responses during phases $\mathrm{Q}$ and 2 in diabetic rats, following $0.5 \%$ formalin injection, appear to be selective for the diabetes-induced abnormality, as no significant effect was observed in control rats by similar treatments. Thus, it appears that $\mathrm{OZ}$ precludes the disruption of normal nociceptive function and can selectively prevent hyperalgesic responses to formalin in diabetic rats.
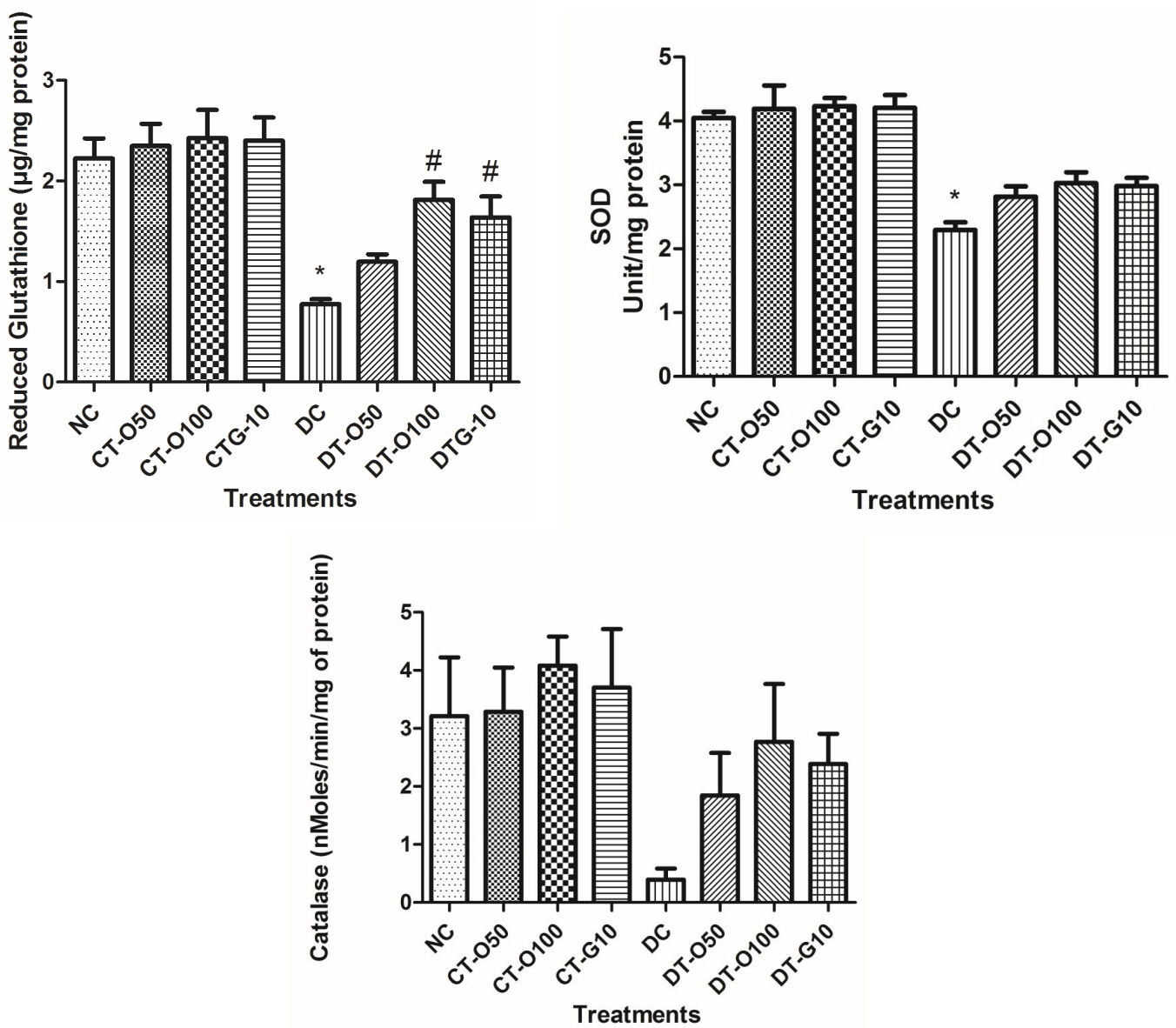

Figure 7. Effect of chronic treatment of oryzanol on (a) reduced glutathione activity (b) superoxide dismutase activity (c) catalase activity in sciatic nerve of rats; $n=8$; Values are expressed in mean \pm SEM; NC: Normal control (no treatment); CT-O50: Control treated animals receiving oryzanol $50 \mathrm{mg} / \mathrm{kg}$, orally per day for eight weeks; CT-O100: Control treated animals receiving oryzanol $100 \mathrm{mg} / \mathrm{kg}$, orally per day for eight weeks; CT-G10: Control treated animals receiving standard glibenclamide $10 \mathrm{mg} / \mathrm{kg}$, orally per day for eight weeks; DC: Diabetic control animals induced with a single i.v. injection of

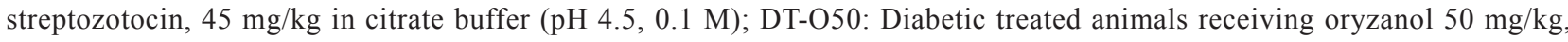
orally per day for eight weeks following STZ injection; DT-O100: Diabetic treated animals receiving oryzanol $100 \mathrm{mg} / \mathrm{kg}$, orally per day for eight weeks following STZ injection; DT-G10: Diabetic treated animals receiving standard glibenclamide $10 \mathrm{mg} / \mathrm{kg}$, orally per day for eight weeks following STZ injection; ${ }^{*} p<0.05$ versus NC, ${ }^{*} p<0.05$ versus DC; Values are obtained by one way ANOVA followed by Tukey's multiple comparison test. 


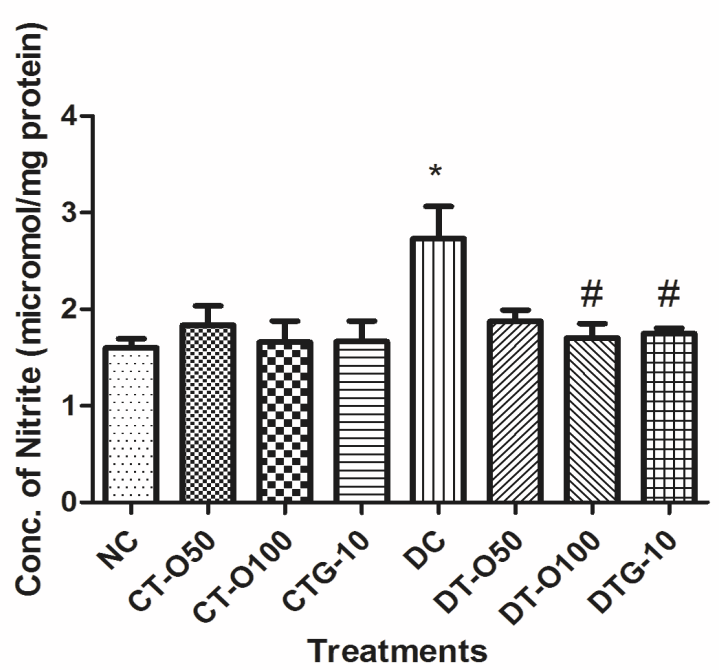

Figure 8. Effect of chronic treatment of oryzanol on nitrite levels in sciatic nerve tissue of rats; $n=8$; Values are expressed in mean \pm SEM; NC: Normal control (no treatment); CT-O50: Control treated animals receiving oryzanol $50 \mathrm{mg}$ / $\mathrm{kg}$, orally per day for eight weeks; CT-O100: Control treated animals receiving oryzanol $100 \mathrm{mg} / \mathrm{kg}$, orally per day for eight weeks; CT-G10: Control treated animals receiving standard glibenclamide $10 \mathrm{mg} / \mathrm{kg}$, orally per day for eight weeks; DC: Diabetic control animals induced with a single i.v. injection of streptozotocin, $45 \mathrm{mg} / \mathrm{kg}$ in citrate buffer ( $\mathrm{pH} 4.5,0.1 \mathrm{M})$; DT-O50: Diabetic treated animals receiving oryzanol $50 \mathrm{mg} / \mathrm{kg}$, orally per day for eight weeks following STZ injection; DT-O100: Diabetic treated animals receiving oryzanol $100 \mathrm{mg} / \mathrm{kg}$, orally per day for eight weeks following STZ injection; DT-G10: Diabetic treated animals receiving standard glibenclamide $10 \mathrm{mg} / \mathrm{kg}$, orally per day for eight weeks following STZ injection; ${ }^{*} p<0.05$ versus $\mathrm{NC},{ }^{*} p<0.05$ versus DC; Values are obtained by one way ANOVA followed by Tukey's multiple comparison test.

The impairment of $\mathrm{Na}^{+}-\mathrm{K}^{+}$ATPase activity in in experimental diabetic neuropathy has been attributed to a number of biochemical alterations possibly dependent on elevated tissue glucose concentrations, such as decrease in the pool of myo-inositol required to maintain normal phosphatidylinositol synthesis (Zhu \& Eichberg, 1991), reduction in 1,2-diacylglycerol (Zhu \& Eichberg, 1990), and fluctuations in protein kinase C (PKC) activity (Kim et al., 1991). In the current study, $\mathrm{Na}^{+}-\mathrm{K}^{+}$ATPase activities were significantly reduced in nerve preparations from diabetic rats as compared to the control animals. OZ supplementation $(100 \mathrm{mg} / \mathrm{kg} / \mathrm{day}$, p.o.) significantly restored the $\mathrm{Na}^{+}-\mathrm{K}^{+}$ATPase activity, possibly by attenuation of oxidative stress (Son et al., 2011) and amelioration of vascular function (Kihara et al., 1991).

Diabetes-induced hyperglycemia is reported to produce neural degeneration via increased oxidative stress by the autoxidation of monosaccharides (Bonnefont-Rousselot, 2002) that causes vascular impairment resulting in endoneurial hypoxia leading to impaired neural function and reduced motor nerve conduction velocity (Callaghan et al., 2005; Pop-Busui et al., 2006). Moreover, it is well established that pain transmission requires the production of reactive oxygen species (Viggiano et al., 2005). Key mediators of glucose-induced oxidative injury such as superoxide anions and nitric oxide combine with each other leading to the formation of peroxynitrite, which exerts direct toxic effects on neural tissues causing neuropathic pain through protein nitration and nitrosylation, lipid peroxidation, DNA damage and cell death (Kim et al., 2003).

Superoxide anions are also involved in some of the prominent hyperglycemia-induced oxidative changes, including activation of aldose reductase and protein kinase $\mathrm{C}$ activity which are further implicated in alterations in pain perception (Kamei et al., 2001). A significantly higher lipid peroxidation levels observed in the sciatic nerve of diabetic animals in the current study have been reported previously (Kamboj et al., 2010; Nickander et al., 1994). OZ, being a potent freeradical-scavenger (Parrado et al., 2003), significantly reduced the extent of lipid peroxidation to near control levels.

The levels of GSH, a potent endogenous antioxidant considered as a first line of defense against free radicals were significantly reduced in the sciatic nerve of diabetic animals in the present study. The observations are in accordance to the previous findings implicating lowered GSH levels in diabetes (Kuzumoto et al., 2006; Arora et al., 2008). Furthermore, abnormal GSH metabolism in diabetes may also enhance TNF- $\alpha$ expression (Sagara et al., 1994). OZ treatment (100 $\mathrm{mg} / \mathrm{kg} / \mathrm{day}$, p.o.) significantly regenerated intracellular GSH content in the sciatic nerve; this might be attributed to endogenous GSH repletion, high freeradical-scavenging capacity (Parrado et al., 2003) and inhibition of TNF- $\alpha$ activity (Islam et al., 2008).

Implication of oxidative stress in the pathogenesis of diabetes is also suggested by the altered expression of antioxidant enzymes such as SOD and CAT (Moussa, 2008). The current study, in agreement with earlier reports (Cui et al., 2008), manifested a significant reduction in the SOD activity in the sciatic nerve preparations of diabetic animals, which might involve non-enzymatic glycosylation (Arai et al., 1987). In addition to GSH and SOD, a decreased CAT activity in diabetes might further reduce the defense mechanisms against free radicals (Kamboj et al., 2010). Improvement in the SOD and CAT activities after OZ administration in the diabetic animals is in similar lines to previously reported restoration of these antioxidant 
enzymes by OZ in the liver (Jin Son et al., 2010; Ismail et al., 2010). Thus, it is evident that the simultaneous reduction in the activities of both SOD and CAT might be the underlying factor for the enhanced vulnerability of the sciatic nerve to hyperglycemia induced oxidative stress. The findings, hence obtained, substantiate that $\mathrm{OZ}$ protects the sciatic nerve from hyperglycemia induced damage by reinstating the levels of both these enzymes. Nitrosative stress (peroxynitrite-induced injury) plays an important role in functional abnormalities associated with motor (MNCV) and sensory nerve conduction velocity (SNCV) deficits and sensory neuropathy in STZ-induced diabetic rats (Obrosova et al., 2007). A marked increase in the tissue nitrite levels was observed in our study which was indicative of nitrosative stress in diabetic animals. OZ treatment $(100 \mathrm{mg} / \mathrm{kg} / \mathrm{day}$, p.o.) significantly attenuated the elevated tissue nitrite levels, possibly by virtue of its inducible NO synthase (iNOS) suppression potential (Nagasaka et al., 2007). Moreover, Rao et al. (2010) had recently demonstrated that the rice bran extracts possess potent nitric oxide scavenging activities and inhibit nitrite formation by directly competing with oxygen in the reaction with nitric oxide.

Based on the present preliminary results, it can be concluded that $\mathrm{OZ}$ treatment significantly ameliorates hyperglycemia-induced hyperalgesia, reduces formalin-induced nociception and attenuates oxidative stress mediated biochemical changes which might be responsible for diabetes induced nerve damage. Thus, $\mathrm{OZ}$ can be considered as a novel antinociceptive agent and can be used as a possible therapeutic option in the treatment of neuropathic pain associated with diabetes mellitus. However, further studies are warranted to elucidate the exact molecular mechanism involved in OZ's antinociceptive effect.

\section{Acknowledgement}

The authors wish to thank the Department of Science \& Technology, New Delhi, India for providing financial assistance (INSPIRE Fellowship: JRF Professional) for carrying out this work.

\section{References}

Aebi HE 1983. Catalase. In: Bergmeyer HU, Bergmeyer J, Grabl M (Eds.). Methods of enzymatic analysis. New York: Verlag Chemie, p. 273-286.

Arai K, Maguchi S, Fujii S, Ishibashi H, Oikawa K, Taniguchi N 1987. Glycation and inactivation of human $\mathrm{Cu}-\mathrm{Zn}$ superoxide dismutase. Identification of the in vitro glycated sites. J Biol Chem 262: 16969-16972.

Arora M, Kumar A, Kaundal RK, Sharma SS 2008. Amelioration of neurological and biochemical deficits by peroxynitrite decomposition catalysts in experimental diabetic neuropathy. Eur $J$ Pharmacol 596: 77-83.

Attal N, Jazat F, Kayser V, Guilbaud G 1990. Further evidence for pain-related behaviours in a model of unilateral peripheral mononeuropathy. Pain 41: 235-251.

Bonnefont-Rousselot D 2002. Glucose and reactive oxygen species. Curr Opin Clin Nutr Metab Care 5: 561568.

Calcutt NA, Jorge MC, Yaksh TL, Chaplan SR 1996. Tactile allodynia and formalin hyperalgesia in streptozotocindiabetic rats: effects of insulin, aldose reductase inhibition and lidocaine. Pain 68: 293-299.

Calcutt NA, Malmberg AB, Yamamoto T, Yaksh TL 1994. Tolrestat treatment prevents modification of the formalin test model of prolonged pain in hyperglycemic rats. Pain 58: 413-420.

Calcutt NA 2001. Modeling diabetic sensory neuropathy in rats. Methods Mol Med 99: 55-65.

Callaghan MJ, Ceradini DJ, Gurtner GC 2005. Hyperglycemiainduced reactive oxygen species and impaired endothelial progenitor cell function. Antioxid Redox Signal 7: 1476-1482.

Cui XP, Li BY, Gao HQ, Wei N, Wang WL, Lu M 2008. Effects of grape seed proanthocyanidin extracts on peripheral nerves in streptozocin-induced diabetic rats. J Nutr Sci Vitaminol (Tokyo) 54: 321-328.

Dobretsov M, Romanovsky D, Stimers JR 2007. Early diabetic neuropathy: Triggers and mechanisms. World J Gastroenterol 13: 175-191.

Drug Information Oline 2012. Gamma Oryzanol. http://www. drugs.com/npp/gamma-oryzanol.html. Accessed on March 2012.

Edwards JL, Vincent AM, Cheng HT, Feldman EL 2008. Diabetic neuropathy: mechanisms to management. Pharmacol Ther 120: 1-34.

Feldman EL 2003. Oxidative stress and diabetic neuropathy: a new understanding of an old problem. J Clin Invest 111: 431-433.

Ghatak SB, Panchal SJ 2011. Gamma-oryzanol - A multipurpose steryl ferulate. Curr Nutr Food Sci 7: 10-20.

Ghatak SB, Panchal SJ 2012a. Anti-hyperlipidemic activity of oryzanol, isolated from crude rice bran oil, on Triton WR-1339-induced acute hyperlipidemia in rats. Rev Bras Farmacogn 22: 642-648.

Ghatak SB, Panchal SJ 2012b. Investigation of the immunomodulatory potential of oryzanol isolated from crude rice bran oil in experimental animal models. Phytother Res doi: 10.1002/ptr.4627.

Ghatak SB, Panchal SJ 2010. Methodical characterization and quantitative estimation of crude oryza sativa bran oil. Int J Chem Anal Sci 1: 181-185.

Gidal BE, Billington R 2006. New and emerging treatment options for neuropathic pain. Am J Manag Care 12: S269-S278. 
Griess P 1879. Bemerkungen $\mathrm{zu}$ der abhandlung der H.H. Weselsky und Benedikt "Ueber einige azoverbindungen". Chem Ber 12: 426-428.

IDF 2011. Global diabetes plan. http://www.idf.org/sites/ default/files/Global_Diabetes_Plan_Final.pdf. Accessed on March 2012.

Ilnytska O, Lyzogubov VV, Stevens MJ, Drel VR, Mashtalir N, Pacher P, Yorek MA, Obrosova IG 2006. Poly(ADPribose) polymerase inhibition alleviates experimental diabetic sensory neuropathy. Diabetes 55: 16861694.

Islam MS, Murata T, Fujisawa M, Nagasaka R, Ushio H, Bari AM, Hori M, Ozaki H 2008. Anti-inflammatory effects of phytosteryl ferulates in colitis induced by dextran sulphate sodium in mice. $\mathrm{Br} J$ Pharmacol 154: 812-824

Ismail M, Al-Naqeeb G, Mamat WA, Ahmad Z 2010. Gammaoryzanol rich fraction regulates the expression of antioxidant and oxidative stress related genes in stressed rat's liver. Nutr Metab 7: 23.

Jin Son M, W Rico C, Hyun Nam S, Young Kang M 2010. Influence of oryzanol and ferulic acid on the lipid metabolism and antioxidative status in high fat-fed mice. J Clin Biochem Nutr 46: 150-156.

Kamboj SS, Vasishta RK, Sandhir R 2010. N-acetylcysteine inhibits hyperglycemia-induced oxidative stress and apoptosis markers in diabetic neuropathy. $J$ Neurochem 112: 77-91.

Kamei J, Mizoguchi H, Narita M, Tseng LF 2001. Therapeutic potential of PKC inhibitors in painful diabetic neuropathy. Expert Opin Investig Drugs 10: 16531664.

Kannan SA, Saade NE, Haddad JJ, Abdelnoor AM, Atweh SF, Jabbur SJ, Safieh-Garabedian B 1996. Endotoxin induced local inflammation and hyperalgesia in rats mince, a new model for inflammatory pain. Pain 66: 373-379.

Katewa SD, Katyare SS 2003. A simplified method for inorganic phosphate determination and its application for phosphate analysis in enzyme assays. Anal Biochem 323: 180-187.

Kidd BL, Urban LA 2001. Mechanisms of inflammatory pain. Br J Anaesth 87: 3-11.

Kihara M, Schmelzer JD, Poduslo JF, Curran GL, Nickander KK, Low PA 1991. Aminoguanidine effects on nerve blood flow, vascular permeability, electrophysiology and oxygen free radicals. Proc Natl Acad Sci USA 88: 6107-6111.

Kim J, Rushovich EH, Thomas PT, Ueda T, Agranoff BW, Greene DA 1991. Diminished specific activity of cytosolic protein kinase $\mathrm{C}$ in sciatic nerve of streptozocin-induced diabetic rats and its correction by dietary myo-inositol. Diabetes 40: 1545-1554.

Kim SY, Lee JH, Yang ES, Kil IS, Park JW 2003. Human sensitive to apoptosis gene protein inhibits peroxynitrite-induced DNA damage. Biochem Biophys Res Commun 301: 671-674.

Konrad RJ, Mikolaenko I, Tolar JF, Liu K, Kudlow JE 2001. The potential mechanism of the diabetogenic action of streptozotocin: inhibition of pancreatic beta-cell $O$-GlcNAc-selective $N$-acetyl- $\beta$-D-glucosaminidase. Biochem J 356: 31-41.

Kuhad A, Chopra K 2008. Lycopene ameliorates thermal hyperalgesia and cold allodynia in STZ-induced diabetic rat. Indian J Exp Biol 46: 108-111.

Kuhad A, Chopra K 2009. Tocotrienol attenuates oxidativenitrosative stress and inflammatory cascade in experimental model of diabetic neuropathy. Neuropharmacology 57: 456-462.

Kuhad, A, Sharma S, Chopra K 2008. Lycopene attenuates thermal hyperalgesia in a diabetic mouse model of neuropathic pain. Eur J Pain 12: 624-632.

Kuzumoto Y, Kusunoki S, Kato N, Kihara M, Low PA 2006. Effect of the aldose reductase inhibitor fidarestat on experimental diabetic neuropathy in the rat. Diabetologia 49: 3085-3093.

Lerma-Garcia MJ, Herrero-Martinez JM, Simo-Alfonso EF, Mendonca CRB, Ramis-Ramos G 2009. Composition, industrial processing and applications of rice bran $\gamma$-oryzanol. Food Chem 115: 389-404.

Lowry OH, Rosebrough NJ, Farr AL, Randall RJ 1951. Protein measurement with the folin phenol reagent. $J$ Biol Chem 193: 265-275.

Malmberg AB, Yaksh TL, Calcutt NA 1993. Anti-nociceptive effects of the GM1 ganglioside derivative AGF 44 on the formalin test in normal and diabetic rats. Neurosci Lett 161: 45-48.

Misra HP, Fridovich I 1972. The role of superoxide anion in the autoxidation of epinephrine and a simple assay for superoxide dismutase. J Biol Chem 247: 3170-3179.

Moron MJ, Diperre JW, Mannervik KB 1979. Levels of glutathione, glutathione reductase and glutathione-Stransferase activities in rat lungs and liver. Biochem Biophys Acta 582: 67-71.

Moussa SA 2008. Oxidative stress in diabetes mellitus. Romanian J Biophys 18: 225-236.

Nagasaka R, Chotimarkorn C, Shafiqul IM, Hori M, Ozaki H, Ushio H 2007. Anti-inflammatory effects of hydroxycinnamic acid derivatives. Biochem Biophys Res Commun 358: 615-619.

Nickander KK, Schmelzer JD, Rohwer DA, Low PA 1994. Effect of alpha-tocopherol deficiency on indices of oxidative stress in normal and diabetic peripheral nerve. J Neurol Sci 126: 6-14.

Obrosova IG, Drel VR, Oltman CL, Mashtalir N, Tibrewala J, Groves JT, Yorek MA. Role of nitrosative stress in early neuropathy and vascular dysfunction in streptozotocin-diabetic rats. Am J Physiol Endocrinol Metab 293: E1645-E1655.

Obrosova IG, Pacher P, Szabó C, Zsengeller Z, Hirooka 
H, Stevens MJ, Yorek MA. 2005. Aldose reductase inhibition counteracts oxidative-nitrosative stress and poly (ADP-ribose) polymerase activation in tissue sites for diabetes complications. Diabetes 54: 234242.

Ohara K, Uchida A, Nagasaka R, Ushio H, Ohshima T 2009. The effects of hydroxycinnamic acid derivatives on adiponectin secretion. Phytomedicine 16: 130-137.

Ohkawa H, Ohishi N, Yagi K 1979. Assay for lipid peroxides in animal tissues by thiobarbituric acid reaction. Anal Biochem 95: 351-358.

Pabreja K, Dua K, Sharma S, Padi SS, Kulkarni SK 2011. Minocycline attenuates the development of diabetic neuropathic pain: possible anti-inflammatory and anti-oxidant mechanisms. Eur J Pharmacol 661: 1521.

Parrado J, Miramontes E, Jover M, Márquez JC, Angeles Mejias M, Collantes De Teran L, Absi E, Bautista J 2003. Prevention of brain protein and lipid oxidation elicited by a water-soluble oryzanol enzymatic extract derived from rice bran. Eur J Nutr 42: 307-314.

Pop-Busui R, Sima A, Stevens M 2006. Diabetic neuropathy and oxidative stress. Diabetes Metab Res Rev 22: 257-273.

Ramabadran K, Bansinath $\mathrm{M}$, Turndorf $\mathrm{H}$, Puig $\mathrm{MM}$ 1989. The hyperalgesic effect of naloxone is attenuated in streptozotocin induced diabetic rat. Psychopharmacology 97: 169-174.

Rao AS, Reddy SG, Babu PP, Reddy AR 2010. The antioxidant and antiproliferative activities of methanolic extracts from Njavara rice bran. BMC Complement Altern Med 10: 4 .

Reagan-Shaw S, Nihal M, Ahmad N 2007. Dose translation from animal to human studies revisited. FASEB $J 22$ : 659-661.

Sagara M, Satoh J, Zhu XP, Takahashi K, Fukuzawa M, Muto G, Muto Y, Toyota T 1994. Inhibition with $\mathrm{N}$-acetylcysteine of enhanced production of tumor necrosis factor in streptozotocin induced diabetic rats. Clin Immunol Immunopathol 71: 333-337.

Sayyed SG, Kumar A, Sharma SS 2006. Effects of U83836E on nerve functions, hyperalgesia and oxidative stress in experimental diabetic neuropathy. Life Sci 79: 777-
783.

Sharma SS, Kumar A, Kaundal RK 2008. Protective effects of 4-amino1,8-napthalimide, a poly (ADP-ribose) polymerase inhibitor in experimental diabetic neuropathy. Life Sci 82: 570-576.

Son MJ, Rico CW, Nam SH, Kang MY 2011. Effect of oryzanol and ferulic acid on the glucose metabolism of mice fed with a high-fat diet. J Food Sci 76: H7-H10.

Sugano M, Koba K, Tsuji E 1999. Health benefits of rice bran oil. Anticancer Res 19: 3651-3657.

Tembhurne SV, Sakarkar DM 2010. Influence of Murraya koenigii on experimental model of diabetes and progression of neuropathic pain. Res Pharm Sci 5: 41-47.

Viggiano A, Monda M, Viggiano A, Viggiano D, Viggiano E, Chiefari M, Aurilio C, De Luca B 2005. Trigeminal pain transmission requires reactive oxygen species production. Brain Res 1050: 72-78.

Vincent AM, Russell JW, Low P, Feldman EL 2004. Oxidative stress in the pathogenesis of diabetic neuropathy. Endocr Rev 25: 612-628.

Zhu X, Eichberg J 1990. 1,2-Diacylglycerol content and its arachidonyl-containing molecular species are reduced in sciatic nerve from streptozotocin-induced diabetic rats. J Neurochem 55: 1087-1090.

Zhu X, Eichberg J 1991. A myo-inositol pool utilized for phosphatidylinositol synthesis is depleted in sciatic nerve from rats with streptozotocin-induced diabetes. Proc Natl Acad Sci USA 87: 9818-9822.

Zullaikah S, Melwita E, Ju YH 2009. Isolation of oryzanol from crude rice bran oil. Bioresour Technol 100: 299302 .

\section{*Correspondence}

Shital S. Panchal

Department of Pharmacology, Institute of Pharmacy, Nirma University

Sarkhej-Gandhinagar Highway, Ahmedabad-382 481, Gujarat, India

shital.panchal@nirmauni.ac.in

Tel: +919687626589

Fax: +91 792717241917 